\title{
Idiopathic chylous ascites following vaginal delivery: A Case report
}

\author{
Erol Arslan ${ }^{1 *}$, Selim Buyukkurt ${ }^{1}$, Ahmet Gokhan Saritas ${ }^{2}$, Cigdem Akcabay ${ }^{1}$ and Mehmet Ozsurmeli ${ }^{1}$ \\ ${ }^{1}$ Department of Obstetrics and Gynecology, Cukurova University School of Medicine, Turkey \\ ${ }^{2}$ Department of General Surgery, Cukurova University School of Medicine, Turkey
}

*Corresponding author: Erol Arslan, Department of Obstetrics and Gynecology, University of Cukurova School of Medicine, Turkey.

\begin{abstract}
Chylous ascites is described as accumulation of chyle in the abdominal cavity. It has several causes like pancreatitis and tuberculosis. Pregnancies those were complicated by chylous ascites were shown in the literature due to that well known causes. By that time there were not any cases that showed vaginal delivery complicated by incidental chylous ascites. In the present study we reported a 19 year-old women who had chylous ascites after vaginal delivery without any potential causes of the disease. She was consultated by general surgeon and explorative laparotomy was decided which did not show any etiologic reason for ascites. After all she was referred to us for further investigation and treatment of the chyle. She was treated conservatively and the drain was removed on post-op 6th. Despite the detailed investigation there was not found any causes that explain the ascites and the increased intra-abdominal pressure during second stage of delivery was thought to be most potential cause of chylous ascites. Patient was discharged on post-op 10 and on long follow up of 6 and 12 months after delivery she was doing well and had no problem.
\end{abstract}

Keywords: Chylous ascites; Intra-abdominal pressure; Pregnancy; Vaginal delivery

\section{Introduction}

Chylous ascites (CA) is the milky, opaque and fatty fluid accumulation in the abdominal cavity. It is usually seen in intra abdominal malignencies and cirrhosis, when the lymphatic vessels are interrupted. Chronical inflamation due to tuberculosis are more prevelant in developping communities. Gallstones and gestational hyperlipidemia are common causes of pancreatitis and CA in pregnancy [1]. CA is rarely seen during the pregnancy and only 15 cases have been published. Here we present a new case and highlight the unique properities of this case.

\section{Case Presentation}

A 19-year-old gravida 3, parity 2 women was admitted to emergency department of a local hospital with complaint of abdominal pain, nausea and vomiting where she had a spontaneous vaginal delivery of a $2800 \mathrm{~g}$ healthy female fetus 2 days ago. She declared that the only problem was nausea and vomiting which started few hours following the delivery. Anti-emetics helped to resolve these compliants for the first day and she was discharged. Day after she suffered from abdominal distention and tenderness; nausea and vomiting. The ultrasound examination revealed diffuse ascites and paracentesis was performed. The appearence of the peritoneal fluid sample was milky and after the consultation with general surgeon it has been decided to explore surgically the abdominal cavity. The amount of the evacuated chylous fluid was $1500 \mathrm{ml}$ and the exploration was unremarkable. On the first day of laparotomy $1000 \mathrm{ml}$ of chylous fluid was drained and the patient was refered to our hospital due to high amount of drainage as well as for investigation of the etiology. Initial evaluation of patient in our institute, revealed abdominal tenderness with voluntary guarding and hypoactive bowel sounds. She was a slim woman and had no past medical history that might explain her CA. Her systolic blood pressure was $120 \mathrm{~mm} / \mathrm{Hg}$ and diastolic was $60 \mathrm{~mm} / \mathrm{Hg}$ and heart rate was 114 beat per minute. Blood chemistry showed the following values: white blood cell 13.6×103/凶l; hemoglobin $10.5 \mathrm{~g} / \mathrm{dl}$; hematocrit $34.4 \%$; platelets $317000 \times 103 / \mathbb{\text { \} } \text { ; amylase }}$ $27 \mathrm{U} / \mathrm{L}$; glucose $101 \mathrm{mg} / \mathrm{dl}$; C-reactive protein $28.2 \mathrm{mg} / \mathrm{dl}$; albumin $2.4 \mathrm{~g} / \mathrm{dl}$; total cholesterol $131 \mathrm{mg} / \mathrm{dl}$ and triglyceride $466 \mathrm{mg} / \mathrm{dl}$. The coagulation tests, kidney and liver function tests were in normal range. Abdominal computed tomography revealed edematous bowel wall, which was consistent with paralytic ileus and nothing 
else was found which might be related with pancreatitis nor tuberculosis. Meanwhile ascites was sent for evaluation and biochemical values of ascites revealed that triglyceride $505 \mathrm{mg}$ / dl; albumin 1.7g/dl; protein $3.1 \mathrm{~g} / \mathrm{dl}$; glucose $56 \mathrm{mg} / \mathrm{dl}$; LDH 541. The treatment of ileus was started which contained bowel rest, nasogastric decompression, rectal enema two times in a day and intravenous hydration, antibiotics and analgesics. Daily abdominal X-ray monitoring showed improvement. From the post-op day 4 she started oral intake and tolerated it well. CA drainage finished on post-op day 5 . The culture of ascites and sputum revealed free from tuberculosis. She was discharged on post-op 10th day. Six and 12 months later, the patient was evaluated and there was not any abnormalities including ascites in the abdomen.

\section{Discussion}

CA is a rare event during pregnancy. It is defined as non-purulent, milky fluid in the abdominal cavity which has a daily volume $\geq 200$ $\mathrm{ml}$ and triglyceride level $\geq 110 \mathrm{mg} / \mathrm{dl}$ [2]. The etiology of the CA are classified as congenital (lymphectasia or lymphatic dysplasia), traumatic (blunt trauma, volvulus, lymphadenectomy), neoplastic obstruction, inflamation (tuberculosis, SLE, Behçet, sarcoidosis) and idiopathic. Some believe that the endocrine mileu of pregnancy may fascilate the leakage from the lymphatic vessels [3]. Due to its rarity, the diagnosis requires high level of suspicion. Nause and vomiting are common but non-specific signs of acute abdomen. Their occurences are unexpected following the childbearing. Blood chemistery showing high triglyceride level and radiologically demonstration of ascites are the first steps of the diagnosis of CA. Radiological examination may also be useful in the evaluation of pancreaticobilier system. Paracentesis permits to collect the sample for macroscopic, biochemical and microbiological examination To best of our knowledge the case presented in this paper is the 16th case of cyhlous ascites complicating the pregnancy. The oldest report was made by Kondrat'ev and the author found that the etiological factor was volvulus of the small intestine [4] Hyperlipidemic pancreatitis is the most frequent reason. Five of the 10 cases of hyperlipidemic pancreatitis leading to cyhlous ascites had famial hyperlipidemia [5]. The remaining five cases had gestational hyperlipidemic pancreatitis [6-10]. Plasmapheresis may be useful in hyperlipidemic patients. The case presented by Sun et al. was releated with aggressive mesenteric fibromatosis [11]. Habek demonstrated congenital dilatation of abdominal lymphatic vessels by lymphangiography [3]. In the two remaining cases the pregnant women had morbid obesity [12] and preeclampsia [1]. These two cases had cesarean section and cyhlous ascites was detected incidentally. Our case is unique regarding the previous ones: she delivered vaginally and symptoms were appearent in the puerperium; absence of underlying pathology was demonstrated surgically and radiologically; her medical and family history were uneventful. We hypothesised that pushing efforts caused rupture of lymphatic vessels which may be more permeable due to placental hormones.

Our case report gives important masages about this rare entity. While chylous nature of the intraperitoneal fluid was detected by paracentesis and radiological evaluation did not reveal any surgical pathology an unnecessary laparotomy was made. In order to reduce morbidity, laparotomy may be reserved if abnormal radiological findings would be detected or progressive disease would be present. In the abscence of the detectable underlying pathology, spontan resolution of CA is usually occurs.

\section{Acknowledgement}

None.

\section{Conflict of Interest}

No conflict of interest.

\section{References}

1. Thompson KA, Al Khabbaz A (2015) Incidental chylous ascites at the time of cesarean section. Case Rep Obstet Gynecol. 2015.

2. Press OW, Press NO, Kaufman SD (1982) Evaluation and management of chylous ascites. Ann Intern Med 96: 358-364.

3. Habek D, Habek JČ, Vujic B (2005) Nontraumatic chyloperitoneum in pregnancy. Eur J Obstet Gynecol Reprod Biol 2005: 122: 245-247.

4. Kondrat'ev NP (1980) Small intestine volvulus complicated by acute chylous ascites in pregnant women. Khirurgiia 2: 90-91.

5. Crisan LS, Steidl ET, Rivera-Alsina ME (2008) Acute hyperlipidemic pancreatitis in pregnancy. Am J Obstet Gynecol 198: e57-e59.

6. Chuang SC, Lee KT, Wang SN, Kuo KK, Chen JS, et al. (2006) Hypertriglyceridemia-associated acute pancreatitis with chylous ascites in pregnancy. J Formos Med Assoc 105: 583-587.

7. Eser Kayatas S, Eser M, Cam C, Cogendez E, Guzin K, et al. (2010) Acute pancreatitis associated with hypertriglyceridemia: a life-threatening complication. Arch Gynecol Obstet 281: 427-429.

8. Gupta N, Ahmed S, Shaffer L, Cavens P, Blankstein J, et al. (2014) Severe hypertriglyceridemia induced pancreatitis in pregnancy. Case Rep Obstet Gynecol. 2014.

9. Liu CJ, Yen CL, Chang JJ, Lee TS, Fan KM, et al. (2001) Chylous ascites in acute pancreatitis during pregnancy: case report. Chang Gung Med J 24: 324-328.

10. Hang Y, Chen Y, Lu LX, Zhu CQ (2013) Acute hyperlipidemic pancreatitis in a pregnant woman. World J Emerg Med 4: 311-313.

11. Sun L, Wu H, Zhuang YZ, Guan YS (2007) A rare case of pregnancy complicated by mesenteric mass: what does chylous ascites tell us? World J Gastroenterol 13: 1632-1635.

12. Babic I, Tulbah M, Ghourab S (2012) Spontaneous resolution of chylous ascites following delivery: a case report. J Med Case Rep 6: 187. 